\title{
Gunshot Injuries of the Maxillofacial Region
}

\author{
Lt Col Rohit Sharma and Maj Anson Jose
}

\subsection{Introduction}

Gunshot injuries to the maxillofacial region in particular present a challenging situation for the facial reconstructive surgeon. These injuries are relatively rare and hence the true incidence is unknown [1]. Feature common to most maxillofacial gunshot injuries is extensive tissue destruction. The degree of tissue loss, depth of the injury, associated necrosis, and concomitant central nervous system (CNS) injuries may not be apparent at initial presentation [2]. Comprehensive management of such wounds is often challenging because of its heterogeneous nature, composite 3D tissue destruction, and complex structural and functional anatomy of the face.

In contrast to blunt facial trauma, the literature on the management of ballistic facial injury is relatively scarce [1]. The management strategies for patients with facial gunshot wounds are almost as diverse as the case presentation itself. While there has been a gradual shift from conservative delayed operative repair to an early aggressive one-stage management approach, the controversies surrounding the timing and extent of intervention have not yet ceased to exist. Such an ongoing debate is largely due to the fact that the majority of treatment outcomes of gunshot facial injuries continue to be unsatisfactory regardless of treatment methodology adopted. On the other hand, new principles have evolved including the early definitive repair of hard tissues with precise anatomic rigid fixation using bone grafts and definitive soft tissue management with local or vascular flaps allowing for early rehabilitation of patients to their pretraumatic appearance. This paradigm shift away from delayed to a more immediate definitive reconstruction has been predominantly due to the widespread use of free tissue

Lt Col R. Sharma $(\varangle)$

Department of Oral and Maxillofacial Surgery,

11 Corps Dental Unit, Jalandhar Cantt, India

Maj A. Jose

Department of Oral and Maxillofacial Surgery, ADC R\&R,

New Delhi, India transfer, diagnostic computed tomography (CT) scan, and deeper understanding about zone of injury in such cases [3].

Presently the management of gunshot injuries comprises the following steps:

1. Conservative debridement followed by fracture stabilization and primary closure

2. Early reconstruction of missing hard and soft tissues

3. Antibiotics and prevention of infection

4. Postoperative physiotherapy and psychiatric assistance

5. Residual deformity correction and oral rehabilitation [3-6]

This review describes the current management strategies, damage control surgery, and basic protocols employed in the management of high-velocity ballistic injuries to the face.

\subsection{Pathologic Anatomy and Classification}

Traditionally gunshot injuries have been classified as penetrating, perforated, or avulsive [7]. As the gamut of injuries continues to evolve, the severity and magnitude of facial ballistic wounds demand an expanded classification and can be appropriately classified based on the wounding effects and terminal location of projectile as:

- Penetrating

- Perforating

- Avulsive

- Blast

- "Chop off" injuries 
Penetrating injuries are caused when a low-velocity projectile pierces the tissues without making an exit wound (Fig. 59.1).

On the other hand, perforating injuries are distinguished by the presence of a definite exit wound in addition to the entry wound (Figs. 59.2 and 59.3). The exit wounds are often larger with ragged or stellate margins. Avulsive injuries are basically penetrating injuries, characterized by an acute loss and destruction of tissue as a consequence of the passage of the projectile within and out of the body (Fig. 59.4). Blast

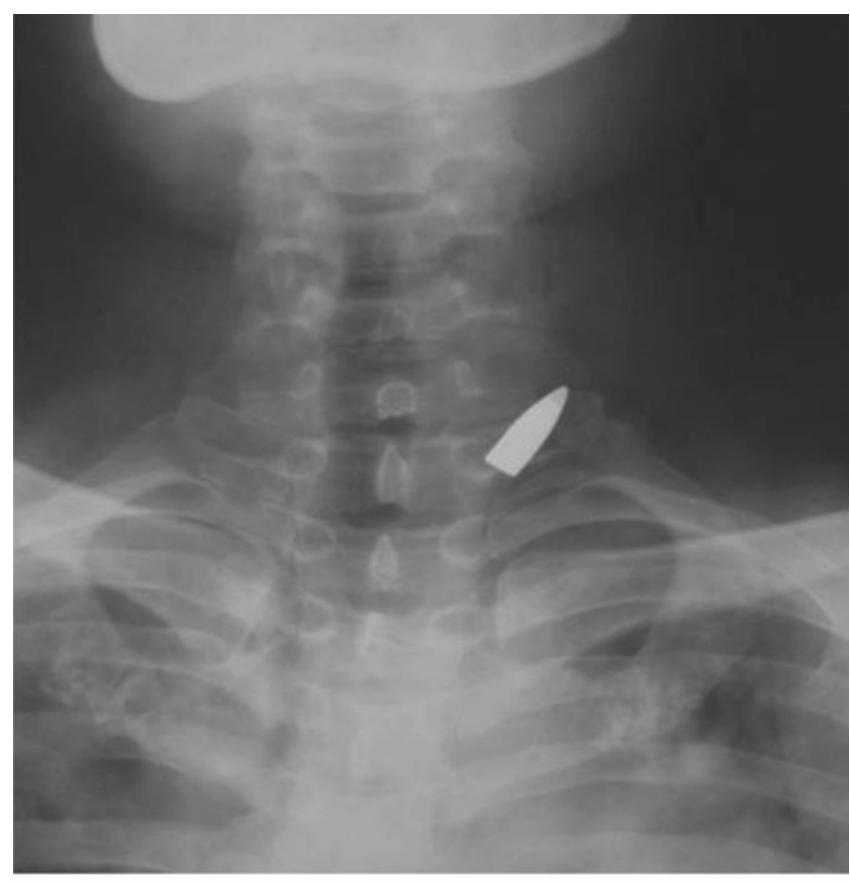

CAssociation of Oral and Maxillofacial Surgeons of India

Fig. 59.1 Penetrating injury with bullet lodged inside the neck

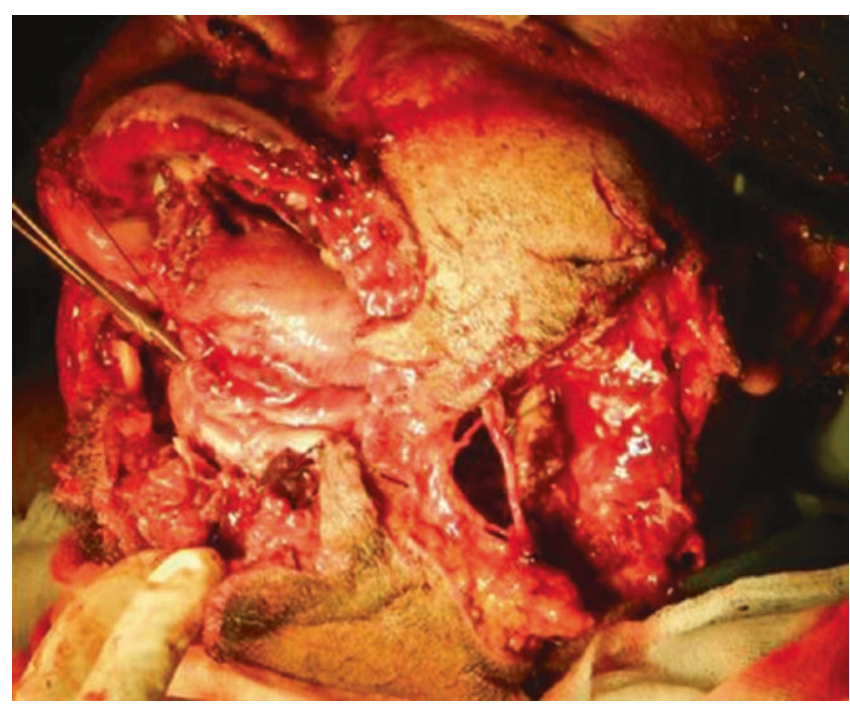

CAssociation of Oral and Maxillofacial Surgeons of India

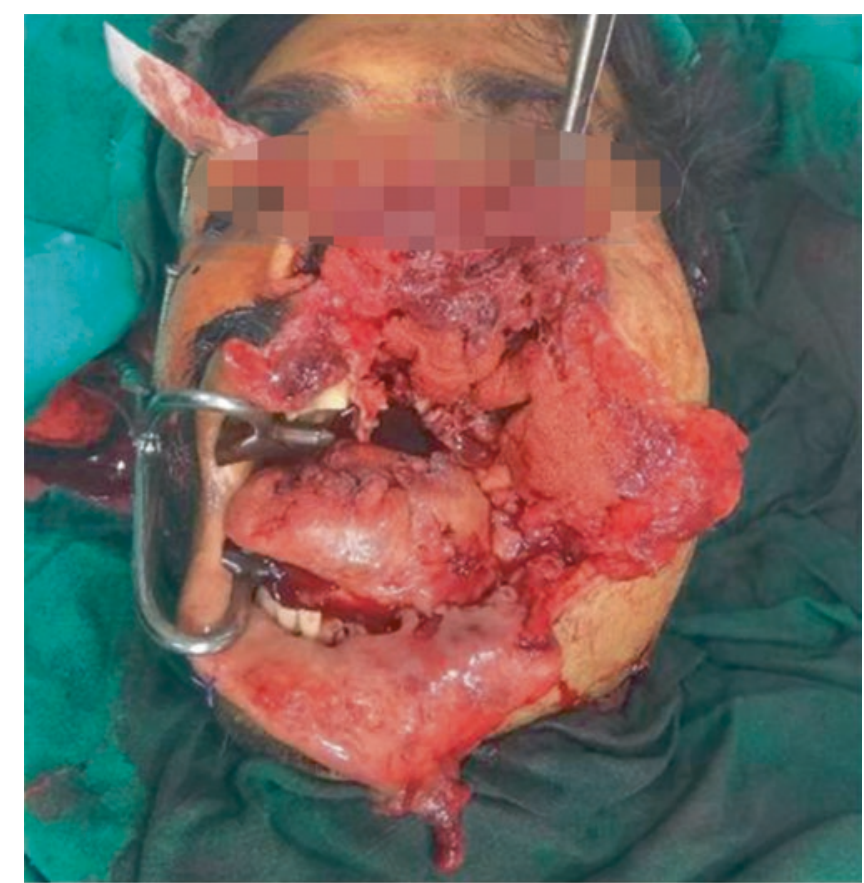

CAssociation of Oral and Maxillofacial Surgeons of India

Fig. 59.3 Avulsive injury of midface caused by a short-range highvelocity impact. The hallmark of high-velocity injuries are comminuted fractures of the facial skeleton with avulsion of soft tissues

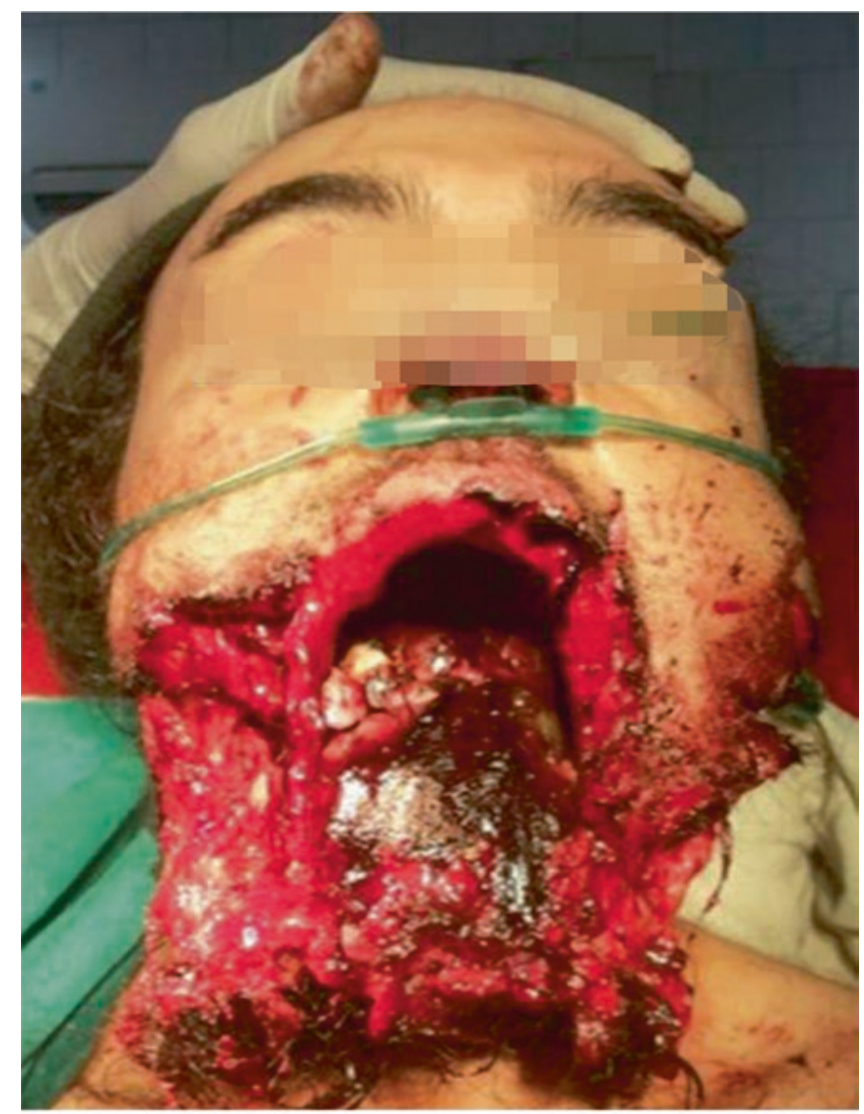

CAssociation of Oral and Maxillofacial Surgeons of India

Fig. 59.2 Perforating injury caused by $7.62 \times 39 \mathrm{~mm} \mathrm{AK-47} \mathrm{rifle.}$ Note the effects of high-energy bullet impact and explosive effects of cavitation on soft tissues resulting in stellate wound margins at the exit

Fig. 59.4 "Chop off" injury with complete avulsion of the mandible and associated soft tissue caused by velocity projectile from a military assault rifle 
injuries are the result of direct or indirect exposure to an explosion caused by military weapons or explosive devises (Fig. 59.5). "Chop off" injuries represent wounds with extensive hard and soft tissue loss as a consequence of highvelocity close-range gunshots [8]. In all these varieties of injuries, the tissue damage is directly proportional to the kinetic energy transferred by the bullet, time taken for the energy transfer, and area over which the energy is transferred. Hence, the type and variant of injury have significant implications in management.

Apart from this conventional nomenclature, various other classifications have been used for categorizing penetrating
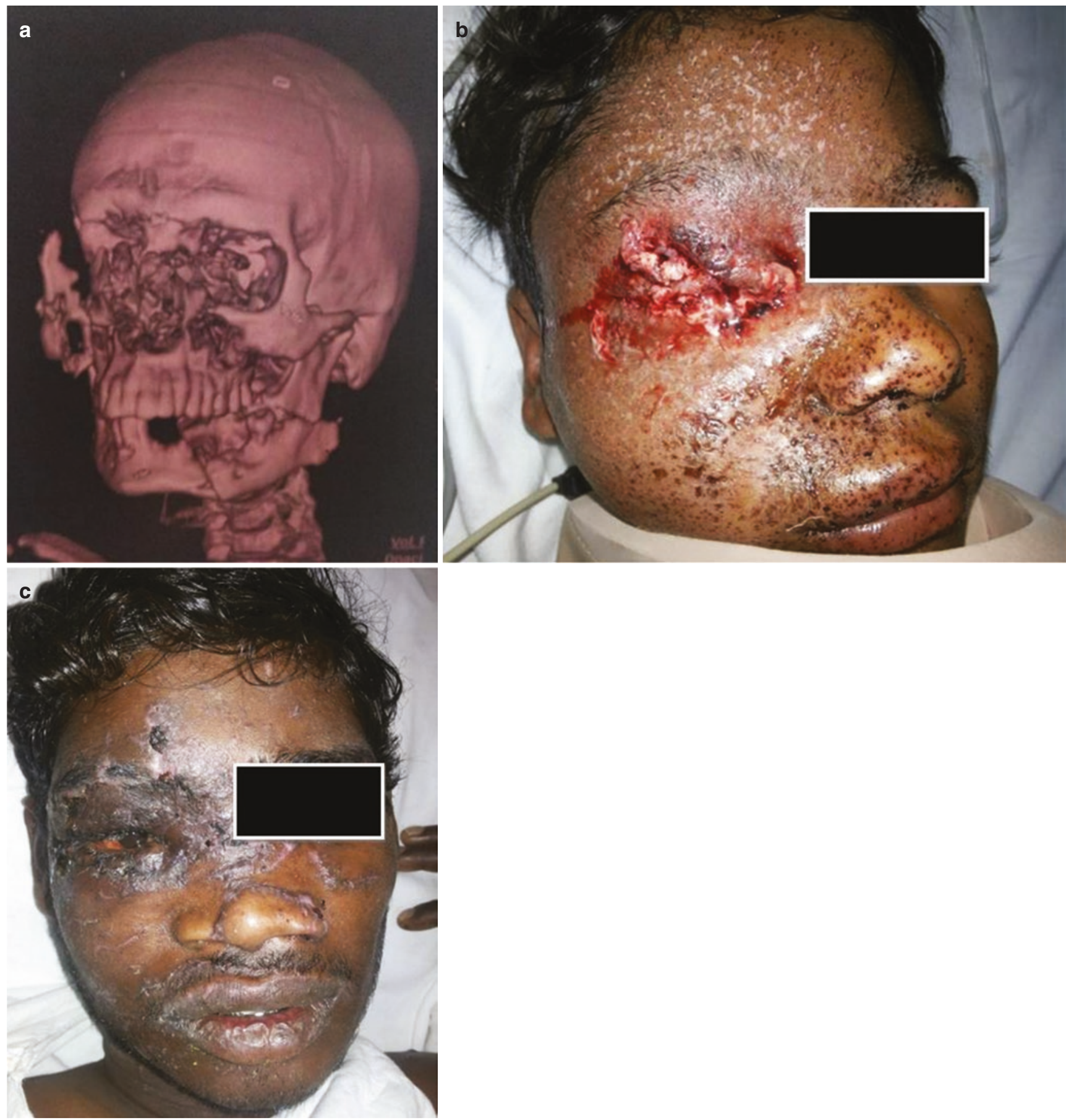

CAssociation of Oral and Maxillofacial Surgeons of India

Fig. $59.5(\mathbf{a}, \mathbf{b}, \mathbf{c})$ Blast injury caused by propagation of shock waves from the projectile. Soft tissue injury is minimal in such cases with severe comminution of the underlying skeleton 
facial injuries; however, its application in clinical scenario is debatable. Similarly, many authors have developed an algorithm for the workup of ballistic wound based on the location of entry wound. Despite having limited application, no significant correlation has been found between site of entrance wound and therapeutic outcome of gunshot wounds [9].

A pragmatic approach to the management of such injuries involves:

1. Establishing an airway

2. Control of hemorrhage

3. Damage control surgery and identifying concomitant injuries

4. Early definitive repair of hard and soft tissues

5. Aesthetic refinements and rehabilitation

\subsection{Initial Evaluation, Triage, and Damage Control Surgery}

Initial management of gunshot wounds is based on the advanced trauma and life support protocols (also refer Chap. 48 of this book). Gibbons and Breeze [10] have elaborated the modified military protocols pertaining specifically to combat-related ballistic facial injuries. These include emergency management procedures that followed the CABC (catastrophic hemorrhage, airway, breathing, circulation) protocol proposed by Hodgetts et al. [11] which focused the need to control catastrophic bleeding as a priority over airway complications in a polytrauma patient. In a parallel manner, initial evaluation and damage control maxillofacial surgery should commence within the golden hour for effective patient management. Damage control surgery may be perceived as an immediate assessment of life-threatening injuries and addressing them promptly by means of early life-saving resuscitation and surgeries [12]. It is not regarded as a separate entity; it is seen as an essential, initial component in the management of any severely injured patient. In order to clear confusion clouding this highly debated area, a proposed set of damage control procedures that can be applied to ballistic maxillofacial injuries involving the maxillofacial region is given (Table 59.1).

Fortunately, the mortality rate directly attributable to maxillofacial firearms injuries is as low as $2-3 \%$ and pre- dominantly due to a compromised airway [10]. Airway compromise is a serious consequence of all gunshot injuries to the face, and it can be due to a direct or an indirect injury to the airway. Injury to tissues and resultant edema in the vicinity of the air passages invariably handicaps the airway indirectly. Additionally, loss of muscle attachments and fractures of the anterior mandible significantly debilitates the airways. Manual repositioning of the fractured segments of mandible and base of tongue are the fundamental measures to be executed to prevent posterior airway collapse. While nasopharyngeal and oropharyngeal airways afford interim relief, endotracheal intubation is the established approach in emergency condition. This however presents a challenge on account of the edema, bleeding, and avulsed soft tissues that may possibly block the airway [13].

In the author's experience, a vast majority of maxillofacial gunshot wounds require surgical tracheostomy. The probability of concomitant intracranial injuries with low Glasgow Coma Scale (GCS) is also high in such patients [14]. Since most patients in this category require prolonged intubation and most gunshot wounds to the face require multi-phased surgical approach, the authors view surgical tracheostomy as having distinct advantage over other methods. Management of hemorrhage and its allied complications are well known in maxillofacial injuries as emphasized by previous writers on war surgery, yet it needs a descriptive analysis owing to the fatality it can cause. Hemorrhage is an inevitable consequence of all gunshot injuries to the face. Management of bleeding is an important aspect of damage control surgery, and adequate hemodynamic resuscitation is essential for the early physiological recovery of the victim [15].

Bleeding from high-energy ballistic injuries is practically impossible to control by external pressure tamponade due to the presence of bony structures and the inherently vulnerable condition of fragile anatomic structures like the eyes, brain, and airway seen in such injuries. In open injury scenario, hemorrhage can be easily managed by meticulous examination to recognize all the bleeding vessels followed by their ligation. Closed injuries necessitate balloon tamponade with Foley catheter (Fig. 59.5) to control bleeding. If bleeding is not controlled by the usual techniques, external carotid ligation or selective embolization method is used, which is by far the most predictable method to control bleeding from external carotid artery and its tributaries $[13,16]$. 
Table 59.1 Algorithm in the treatment of Gun Shot Wounds (GSW)

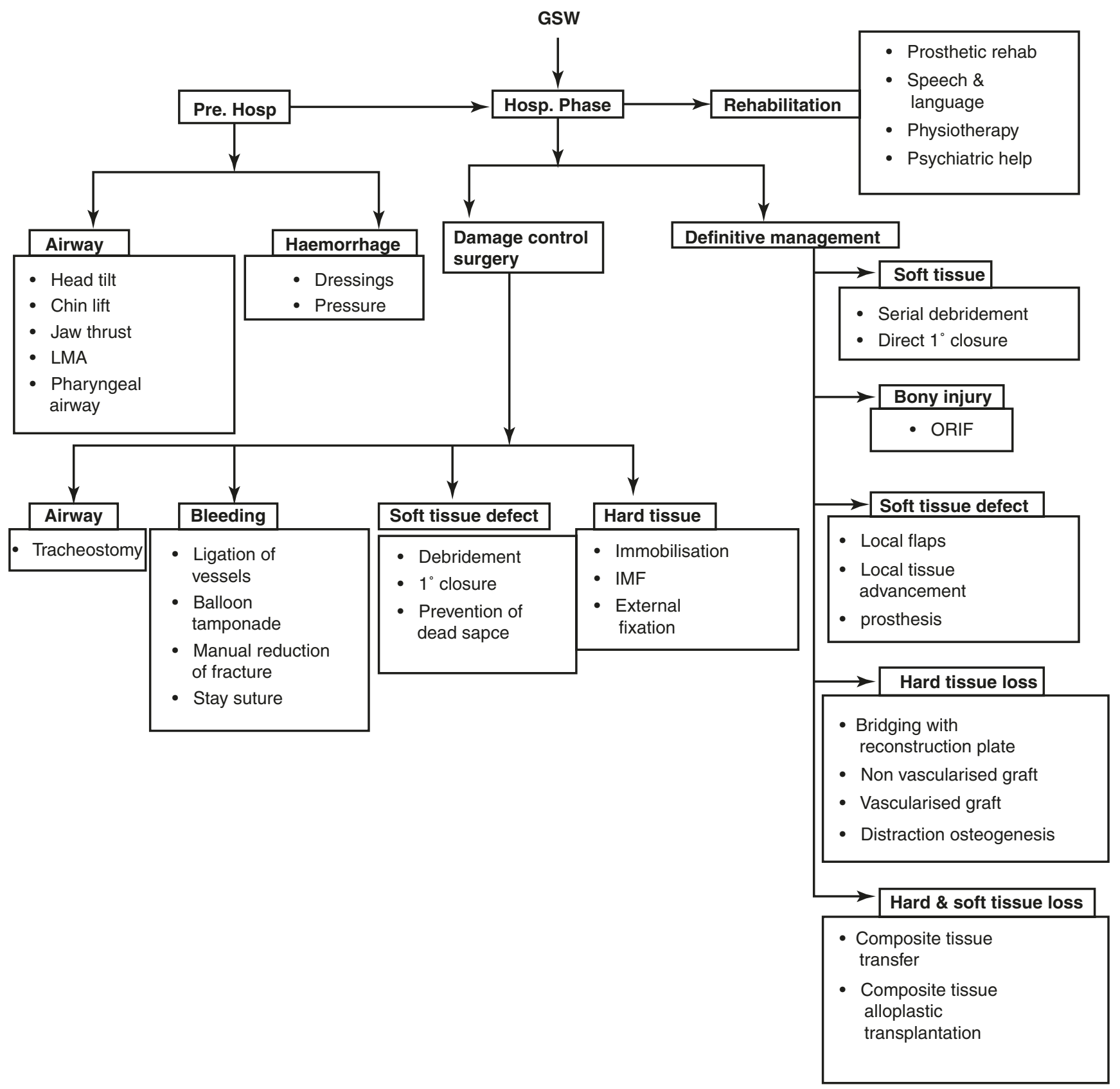

\subsection{Diagnostic Imaging}

Once airway is secured and bleeding is controlled, attention should be directed toward radiological assessment of the injury. Depending on the severity of injury a plain X-ray, CT scan and CT angiography can be requested [15]. The extent of injury, degree of hard tissue fragmentation, location of metallic splinters, damage to $\mathrm{C}$-spine, and any occult brain injuries can be easily delineated with the help of a CT scan. Similarly, involvement of great vessels, any concealed bleeding, and flow dynamics of vessels suitable for microvascular reconstruction can be studied using CT angiogram. Apart from the damage characteristics of the wound, another crucial factor which needs to be assessed during radiological examination is the status of $\mathrm{C}$-spine.

Any injury of such magnitude enough to fracture the facial skeleton can invariably cause an occult $\mathrm{C}$-spine injury. The incidence of $\mathrm{C}$-spine injuries varies from 8 to $11 \%$ in all maxillofacial traumas [17]. Hence, potential cervical spine injury should be always considered unless proven otherwise clinically or radiologically. It is pertinent to immobilize the cervical spine to prevent further damage especially in unconscious patient (Fig. 59.6). However, substantial evidence is still lacking about the safety and efficacy of cervical collars 

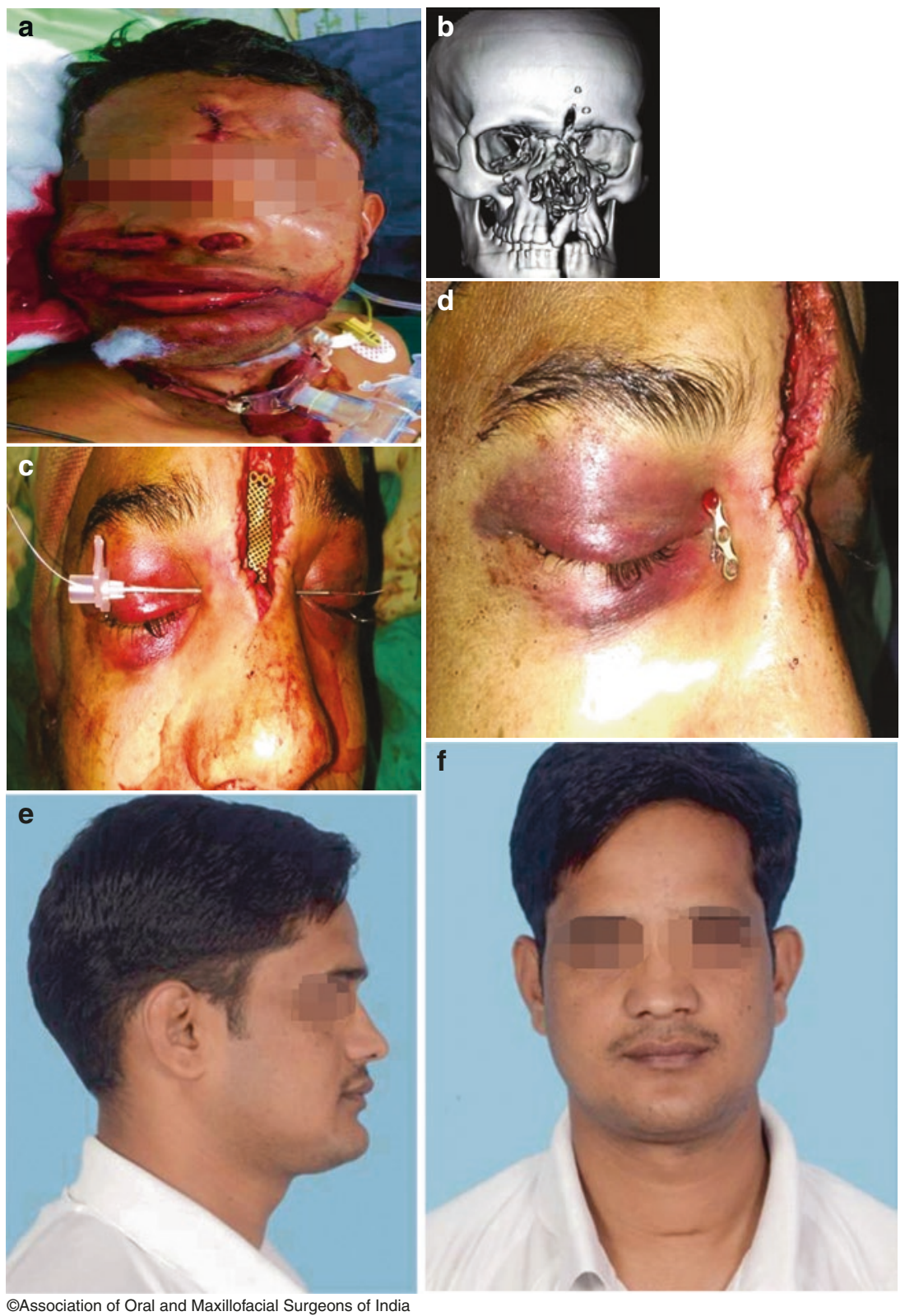

Fig. 59.6 (a-e) Low-velocity close-range handgun injury-3D CT

iv cannula and wire. Three years post-surgery-adequate restoration of showing comminution of maxilla and NOE complex. The case was treated by ORIF mandible, maxilla, frontal bone, and cathopexy using width and projection of midface 
used in such injuries. Moreover, placement of rigid collars interferes during airway management, central line placement, and definitive repair of facial injuries [13].

\subsection{Definitive Management of Facial Gunshot Wounds}

The prime goal in the management of facial gunshot wounds is to rehabilitate the patient to pre-injury function and aesthetics. However, it is not always easy to get a flawless postoperative outcome with one particular treatment modality or a particular surgical technique. Hence, the treatment should be timed and tailored depending upon the type and severity of the injury, amount of tissue loss, general health status of the patient, surgeon's expertise, and availability of resources. Before initiating any treatment procedures, a thorough assessment of the wound by a multidisciplinary team is imperative as gunshot injury cases are seldom comparable. A comprehensive evaluation and discussion by a diverse panel gives the surgeon valuable perspectives which in turn has a positive impact on the final outcome.

\subsection{Debridement}

Modern high-velocity firearms transfer heavy cavitation energy inside tissues causing physiological and morphological alterations resulting in hemorrhage, thrombosis, and necrosis [18]. The tissue response toward the high-velocity projectile varies with the type of tissues and elastic deformation it can sustain. The dermis is viscoelastic, and injuries will result in abrasion, traumatic tattooing, and contusion particularly in close-range shots. Muscle tissues can withstand elastic deformation up to four times the size of the projectile, but at a cellular level, it may undergo significant necrosis, devitalization, and denaturation rendering the microenvironment favorable for bacterial multiplication [19]. The injuries to neurovascular bundles behave similar to muscles, thereby causing tearing, shearing, and rupture of blood vessels. At microscopic level, all the three layers of blood vessels get affected resulting in the formation of thrombus, inflammation, and persistent spasm [20]. Cortical bone on the other hand is crystalline in consistency; therefore, penetrating injury causes fragmentation of bone with formation of multiple secondary projectiles. Conventional management of firearm injuries involves initial wound debridement, wound toilet, adequate soft tissue closure, and administration of antibiotics followed by delayed repair of deformities [4]. However, with the advent of vascular flaps and new reconstruction methods, there has been a colossal shift in the management of such injuries to a more definitive early single-stage repair [21].
The management commences with meticulous debridement of wounds to the point of active surgical bleeding. This strategy is particularly important in case of crushed and contaminated wounds wherein the active surgical bleeding encourages the formation of a healthy granulation tissue [18]. Furthermore, it also improves adequate microcirculation at wound margins, thereby promoting rapid healing and tissue resistance to infection. A serial debridement with judicious excision of the necrotic and non-contractile muscle tissues is done to achieve a wound with non-contaminated healthy margins [22].

After generous tissue excision, debridement should be assisted with soft scrubbing brushes and copious irrigation. Removal of deeply embedded splinters or metallic foreign bodies is controversial regarding any particular clinical benefits it offers [10]. The wound debridement should be prompt, and any delay (6-12 h) further complicates the wound management by progressive tissue necrosis. The development of progressive necrosis is a salient feature of gunshot wounds, and contrary to the popular belief, the tissue necrosis is not directly related to energy transfer but rather to the depth of tissues destroyed by the movement of the projectile. Animal studies have shown that beyond that critical time period, identification of necrotic margins will be difficult and hence it complicates the debridement and surgical control of the wound [23].

There are two main areas of conflicts pertaining to debridement in gunshot wounds. Many authors recommend immediate careful conservative soft tissue excision followed by secondary debridement of all tissues with questionable viability at a later stage $[24,25]$. These researchers are of the view that it is practically impossible to distinguish between vital and non-vital tissues at initial intervention. On the contrary, a few other professionals believe in single-stage radical debridement on initial intervention [26].

Experimental evidences have shown that the extent of tissue necrosis after gunshot injury is $2 \mathrm{~mm}$ and $8 \mathrm{~mm}$ from the wound margins in skin and muscle tissues, respectively. In bony skeleton, it may extend up to $5 \mathrm{~mm}$ from the fracture line [27]. Thus, there is no convincing evidence to preserve fragmented bone of $1 \mathrm{~cm}$ or less during debridement even if it is attached to soft tissues. Similarly, a serial debridement of such wound is often required to deal with the evolving pattern of tissue necrosis over a period of 24-36 h. This allows for early identification of the demarcation zone between vital and non-vital tissues before reconstructive procedures are planned. The consensus of radical wound debridement at initial intervention aims to remove foreign bodies, necrotic tissues, and microbial contamination as early as possible. It also minimizes inflammation, prevents infections, and helps in achieving favorable wound healing. Any late wound management in our opinion eventually increases the chances of infection, operating time, toxemia, and subsequent surgical intervention. 
Concomitant injuries to salivary gland ducts and facial nerve are often encountered during initial debridement. The ducts and facial nerve are usually tagged with Prolene sutures for future repair. Most of the ductal injuries can be managed by cannulation and primary repair or by rerouting it into oral cavity. Non-salvageable glands should be removed without hesitation to prevent sialocele, salivary fistula, and complicated wound healing. Damage to facial nerve is mainly by thermal, avulsion, and stretch injury caused by the cavitation. Preferably the nerve should be repaired within $72 \mathrm{~h}$ for predictable results. Lacerated nerve is repaired primarily by coaptation or using nerve grafts harvested from greater auricular nerve. The nerve damage caused by cavitation may extend as far as $1.8 \mathrm{~cm}$ from the bullet track, and that should be considered during nerve grafting procedure [19]. Any facial nerve injury anterior to a line connecting mental foramen and lateral canthus is generally not repaired as spontaneous recovery is very likely in such cases.

\subsection{Infection and Role of Antibiotics}

Ballistic facial injuries are often compound and contaminated with high propensity for infection (class IV wounds). Contrary to the popular belief, all ballistic injuries are inherently contaminated, and the infection is primarily by the inoculation of microorganisms carried by the bullet and secondarily as a result of wound contamination in transit or in hospital environment. The actual incidence of infection rates remains elusive and ranges from 7 to $100 \%$ of all military facial injuries [28]. However, a general consensus is lacking in the timing, choice, and duration of antimicrobial therapy in combat injuries. Nonetheless the usage of broad-spectrum antibiotics for 10-14 days which provides cover against staphylococci, Clostridium perfringens, and Acinetobacter baumannii is commonly used [14, 29]. The critical level of bacteria required for initiating an infection reaches peak at $6 \mathrm{~h}$ of injury ( $10^{5}$ bacteria/gm. of tissue), and studies have shown that early administration of antibiotics is paramount and any delay of greater than $6 \mathrm{~h}$ renders the treatment ineffective [30]. The accepted guidelines for combat-related injuries recommend administration of short-course, broadspectrum antibiotics preferably within $3 \mathrm{~h}$ of injury [31]. The use of antibiotics is an adjunct to scrupulous debridement for the prevention of infection and should always be considered in the initial management of ballistic injuries.

\subsection{Soft Tissue Reconstruction}

Gunshot wounds result in composite 3D defects with involvement of the skin, musculature, facial skeleton, and mucosa. The various reconstruction methods for wounds of these natures are prosthetic obturation, non-vascularized grafts with local tissue advancement, loco-regional flaps, and free flaps for large composite defects (Also refer Chaps. 86 and 88 of this book). Before initiating the reconstructive procedure, it should be kept in mind that the management of such wounds is often complicated by the ambiguity in prognosis caused by tissue loss, progressive necrosis, and infection. Therefore most critical facet while handling avulsive wounds lays in achieving and maintaining a favorable intraoral wound closure to minimize the chances of wound infection and wound dehiscence due to oral contamination [32]. It is always crucial to close the wound primarily because of the high propensity toward scaring and functional debility of wounds that heal secondarily. Most gunshot wounds can be closed primarily, and delayed wound closure in maxillofacial region is rarely necessary. However, two exceptions to this are (1) wounds which are not possible to debride completely at initial operation and (2) wounds with questionable vitality of tissues.

Sequencing of primary reconstruction of oro-facial region should follow an inside-out principle [33]. The injuries of the oropharynx are first addressed by repairing the musculature and mucosa. This is followed by repair of oral mucosa, floor of the mouth, and the tongue. The reconstruction of lips, cheeks, and other extra-oral tissues is performed later after oral cavity has been reconstructed. Nonetheless if an acceptable intraoral closure is difficult to achieve, a maxillomandibular fixation is done, and it is prudent to leave the wound to heal secondarily. While selecting a reconstructive option, it is important to consider a treatment plan which reduces the treatment time, patient morbidity, number of surgical intervention, and hospital stay [34]. The best possible function and aesthetics are achieved when debridement and reconstruction of hard and soft tissues are done at an early stage and the residual soft tissue deformities are addressed at a later stage with revision surgeries and local flaps [2]. Extra-oral wounds that cannot be closed primarily due to excessive tissue loss are best managed by employing local, regional pedicled flaps and microvascular flaps.

Use of local flaps and regional flaps at the initial operation appears to be most favorable as far as aesthetics and function 
are concerned (Fig. 59.6a). Motamedi [2] advised early use of local flaps in patients with gunshot wounds of the face. He reviewed 30 GSW patients and reported excellent cosmetic and functional outcomes. However, the disadvantages of local flaps are that composite defects cannot be addressed and its availability, limited bulk, and pedicle length. Local tissue rearrangements and local flaps with nonvascular grafts like iliac crest, rib, or cranium can be used for small defects. But large 3D defects and poorly vascularized surrounding tissues caused by cavitation often preclude the use of bone grafts with local tissue rearrangements unlike in tumor reconstruction.

Major avulsive and chop off injuries demand vascularized bone grafts with skin paddle for their reconstruction. Composite free tissue transfer is predictable, provides adequate bulk of well-vascularized tissue to fill the dead space, rehabilitates the buttresses, and reinstates the soft tissue envelope in a limited period of time [15]. The variables affecting the selection of flap depend on the type and amount of tissue loss, location, length of pedicle, donor site injury, and, certainly, surgeon's preference. The most commonly used flaps for facial reconstruction are anterolateral thigh flap, radial forearm, and fibula with skin paddle [5]. It is obligatory to reconstruct both bone and soft tissues in composite defects, and without osseous support, soft tissue-only reconstruction tends to droop over time. After primary healing, the flap is contoured, subsequently unaesthetic skin paddle is excised, and local tissue can be re-advanced for better aesthetic outcomes. Similarly, if adequate vascularized tissue is not used for reconstruction, complications like scar contracture, bone graft resorption, fistula formation, and ultimately collapse of facial envelope will result.

It is clear that reconstruction of avulsive facial defects with free flap should be addressed as early as possible to prevent soft tissue contracture. Nonetheless, how much grace period is required before initiating a free flap reconstruction for optimizing the reconstructive outcomes is still not clear. High-energy cavitation in soft tissue may temporarily damage the local vasculature and hemodynamics at a distance from the margin of permanent wound. While planning a treatment based on microvascular reconstruction, it is imperative to have a conception of the zone of injury in its actual extent. Animal studies have shown that it is safe to place an anastomosis $3 \mathrm{~cm}$ away from the margin of wound track [35]. Furthermore, experimental evidences have shown superior results in integrity and patency of facial vessels anasto- mosed 3 days after injury than those repaired immediately after the injury [20]. If it is so, a composite free tissue transfer as a part of immediate reconstruction in avulsive ballistic injuries should be delayed till 3-4 days. This time period helps in adequate assessment of the extent of devitalized tissues, formulating a treatment plan based on available resources and optimizing the results by executing the treatment before the onset of soft tissue fibrosis and when the blood vessels are devoid of spasm.

Despite several arguments favoring immediate reconstruction for excellent aesthetic outcomes, it is to be noted that scar contracture is inevitable irrespective of the timing of treatment and reconstruction method adopted, although the frequency is more with delayed treatment [36]. Therefore, a review to determine the need for secondary corrective procedures should be conducted in consultation with the interdisciplinary team. Scar contracture is usually managed later by revision surgeries after the maturation of scar. The total number of revision surgeries required for a free flap is less as compared to local or regional flaps. The outcomes of revision surgery depend on the type of flap used, complexity of the defect, and location of the defect with nasal, orbits, and lips requiring the highest number of aesthetic refinements [5]. Similarly other expected soft tissue complications like trismus, microsomia, and other functional disabilities can be addressed by fat grafting, coronoidectomy, commissuroplasty, and Botox injections [37]. Very often the reconstructive surgeries of aesthetically prominent regions of the face like nose and orbits are always suboptimal, and in such cases, prosthetic rehabilitation can be considered even though not physiological and patient compliance is less.

\subsection{Fracture Stabilization and Hard Tissue Reconstruction}

The methodology for treatment varies and ranges from:

1. Debridement only

2. Debridement and closed reduction with or without fixation

3. Debridement, open reduction, and plate osteosynthesis 
In patients without continuity defect, infection and minimal comminution open reduction and internal fixation (ORIF) is simultaneously done along with debridement at the initial stage.

Once initial stabilization is ensured, fixation is generally accomplished by miniplates or reconstruction plates. However, wounds with limited soft issue coverage require a different strategy as the granulation tissues may fail to cover thickness of plate resulting in subsequent plate exposure. Thus, if adequate soft tissue cover cannot be achieved, debridement, external pins, and maxillomandibular fixation (MMF) are the method of choice [33]. Until the introduction of surgical screws and plates, closed treatment was the preferred mode of treatment. The treatment ideology was directed to treat the whole wound as a "bag of bones" using external fixation or MMF in order to avoid periosteal stripping and devitalization of small fragments of bone. Although this therapeutic concept is advocated by several authors, who have reported significantly lesser rates of infection with this technique when compared with ORIF and plates, the value approach continues to be underestimated [38].

The advantages of external fixation are manifold. It helps to prevent bone devascularization, allows for bone regeneration, and also provides adequate support to the comminuted fracture fragments. Additionally, it also enhances the osteogenic potential of the injury site by helping in spontaneous bone regeneration. This phenomenon is more commonly seen in young patients due to hypoxia and acidosis-induced activation of local bone morphogenic proteins (BMPs). The high-velocity trauma causes extensive damage to adjacent muscles and periosteum. This damage along with the effects of local inflammation, hypoxia, and increased carbon dioxide concentration activates BMPs resulting in spontaneous bone formation. The concept and knowledge regarding facial buttress and its implication in trauma management have added a new dimension in the functional and aesthetic reconstruction of the face. As a result, internal fixation using locking plates has greatly replaced external fixators over a period of time. It is currently the most widely used technique in management of GSWs with bone loss and is used if the fracture fragments are large enough to accept screws.

Additionally, bone defects if any should be grafted with harvested iliac crest, ribs, or cranium depending upon the size of the defect (Fig. 59.7). However, the infection rates associated with internal fixation are comparatively higher as quoted by many authors. The increased rates of infection associated with ORIF are due to loosening of hardware and subsequent micromotion at the fracture site and possibly by contamination by oro-nasal flora. Motammedi [2] reported that it is almost impossible to achieve occlusion without arch bars and MMF in majority of gunshot fractures. Presently ORIF along with arch bars continue to be the mainstay in the management such patients. With the advent of new techniques of reconstruction supplemented by innovative plates and screws, vascular grafts and antibiotics have heralded a paradigm shift in the treatment philosophy. Current principles clearly favor early definitive reconstruction of hard tissues with ORIF using rigid fixation supplemented by MMF and bone grafts whenever required (Fig. 59.8).

\subsection{Timing of Definitive Reconstruction}

An area of ongoing debate and controversy in the management of gunshot wounds of the face is regarding the timing of definitive reconstruction [6,39]. Although previous teachings and practices were in favor of delayed reconstruction, the more recent studies demonstrate predictable functional and aesthetic outcomes with immediate definitive reconstruction [40-42]. Scientific studies suggest carrying out definitive reconstruction within a time frame of $48 \mathrm{~h}$ would yield the best possible outcome [2].

Advocates of delayed reconstruction believe that the delay in treatment reduces the probability of infection, necrosis, and postoperative wound complications exponentially. Additionally delay in treatment reduces the chances of mortality and morbidity due to infection and progressive tissue necrosis [43, 44]. Any increase in postoperative temperature, raised leukocyte counts, and other local signs of infection may invariably cause a failure in flap due to risk of venous thrombosis. It has also been suggested that the decreased inflammation and edema aid surgeons to have a better assessment of the extent of injury, thereby helping in precise and desired treatment planning which in turn could lead to a better outcome. Therefore in their opinion, it is prudent to wait before applying any principles of primary reconstruction until a healthy tissue bed is achieved. On the other hand, the disadvantages of delayed treatment are increased treatment time, prolonged hospital stay, increased cost of treatment, and patient distress caused by psychosocial impact of disfigurement associated with gunshot injury (Tables 59.2 and 59.3).

Advocates of early primary treatment claim superior functional and aesthetic outcomes, early restoration of facial form, and limited hospital stay with early return to normal 

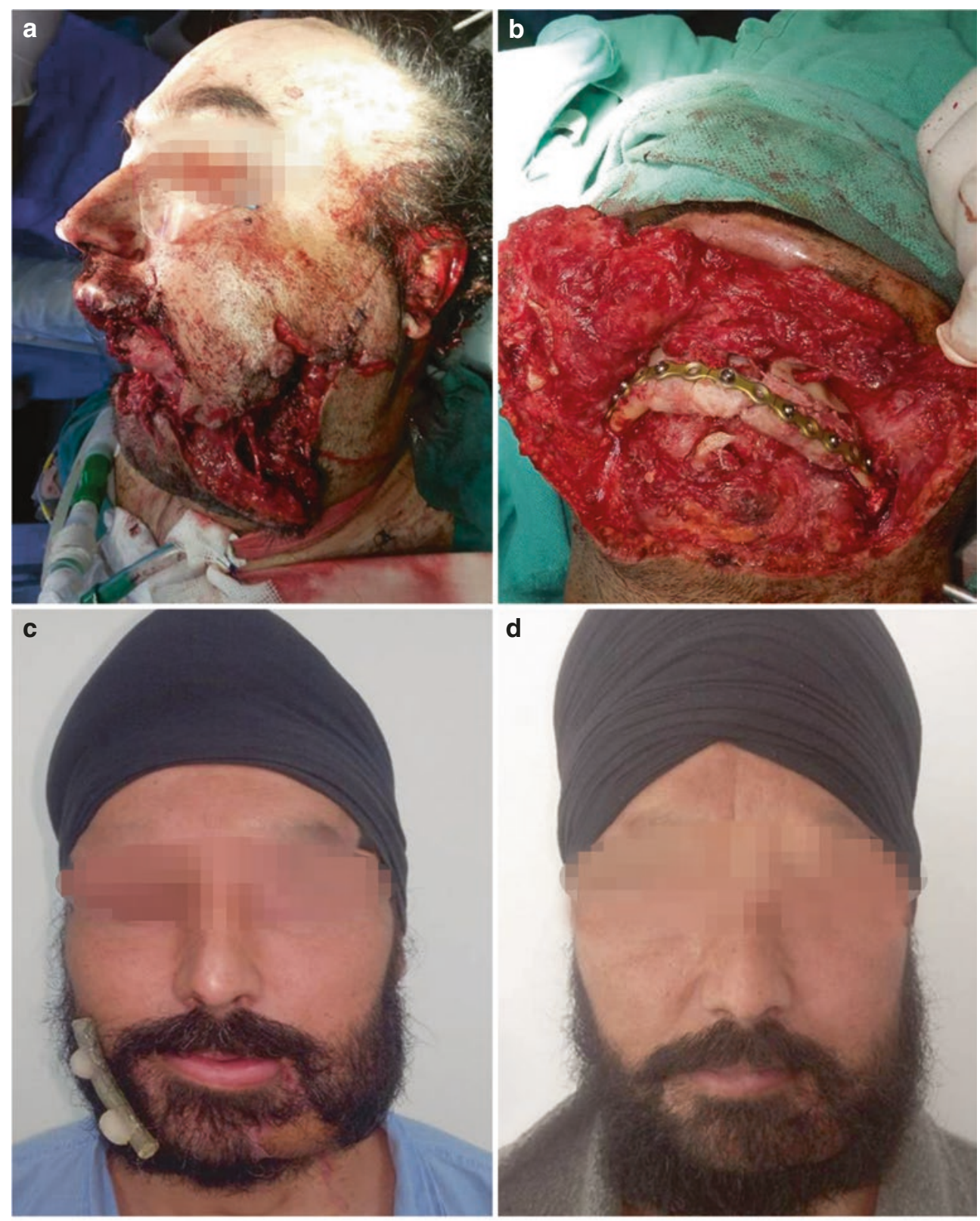

CAssociation of Oral and Maxillofacial Surgeons of India

Fig. 59.7 (a-d) High-velocity close-range assault rifle injury with comminution of mandible and soft tissue loss. Managed initially by non-vascularized graft and later by free fibula osteocutaneous flap

function $[4,14,45]$. These benefits are predominantly due to the elimination of soft tissue contracture by proper anatomic coverage of soft tissue at an early stage [21]. Vasconez et al. [42] compared the infection rates of gunshot wounds that have been managed by early and late reconstruction in a series of 33 cases. In their observation, they could not found reconstruction. External fixator for stabilizing fibula in place. Follow-up after complete treatment

any significant difference in infection rates between the two groups. However, the delayed group showed an apparent increase in the incidence of scar contracture with significant functional and aesthetic complications. Similarly, several other studies have also reported excellent clinical outcomes when immediate reconstruction is carried out [46]. 

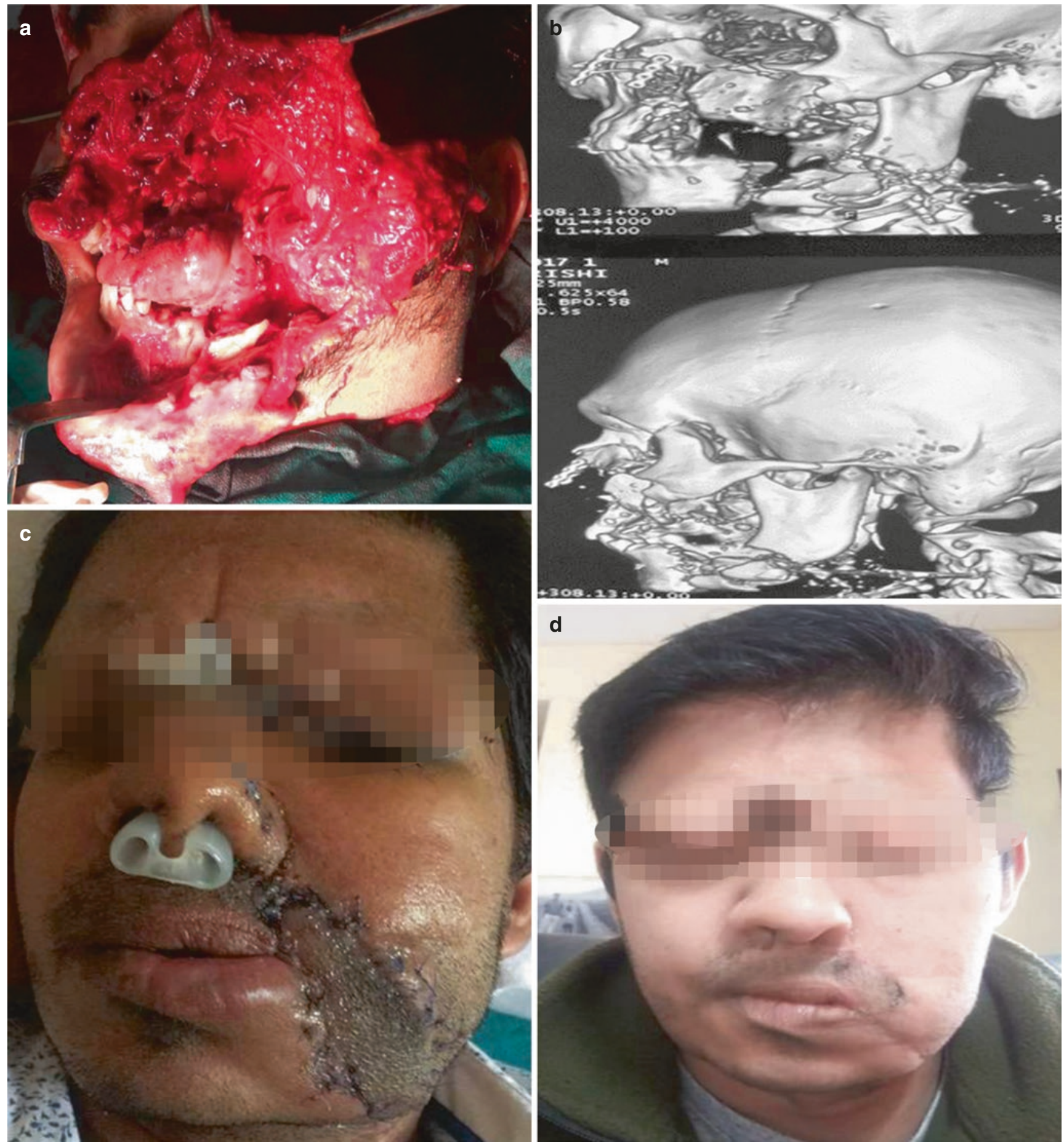

(c)Association of Oral and Maxillofacial Surgeons of India

Fig. 59.8 (a-d) High-velocity assault rifle injury to the face with loss of hemimaxilla and mandible along with partial loss of upper lip was done. Reconstruction of the upper lip by hair-bearing submental island flap. Mandible reconstruction is performed by vascularized fibula

Definitive management of most maxillofacial injuries is not a surgical emergency, and treatment is often delayed in polytrauma patients. A standard consensus for delaying treatment and adopting a staged approach in such cases is due to the inability of a critically injured patient to undergo surgical intervention. However, as soon the patient is deemed to be medically stable, operative intervention targeted toward managing the facial injuries should be initiated. It is imperative to address the bony and soft tissue injuries soon after the resolution of edema and before the initiation of fibrosis of 
Table 59.2 Advantages and disadvantages of immediate reconstruction

\begin{tabular}{l|l}
$\begin{array}{l}\text { Advantages of immediate } \\
\text { reconstruction }\end{array}$ & $\begin{array}{l}\text { Disadvantages of immediate } \\
\text { reconstruction }\end{array}$ \\
\hline $\begin{array}{l}\text { Less scar contracture, } \\
\text { better postoperative } \\
\text { function and aesthetics }\end{array}$ & $\begin{array}{l}\text { The margins of devitalized tissues and } \\
\text { its extent cannot be appreciated during } \\
\text { early repair }\end{array}$ \\
\hline $\begin{array}{l}\text { Early return to function } \\
\text { and less hospital stay }\end{array}$ & $\begin{array}{l}\text { Correction of subtle deformities is } \\
\text { difficult and such minor correction } \\
\text { always requires second intervention }\end{array}$ \\
\hline $\begin{array}{l}\text { Less psychological impact } \\
\text { on patient because of early } \\
\text { recovery }\end{array}$ & $\begin{array}{l}\text { Surgeon's expertise and availability of } \\
\text { resources }\end{array}$ \\
\hline $\begin{array}{l}\text { Proper anatomical } \\
\text { coverage of defect so } \\
\text { chances of infection are } \\
\text { less }\end{array}$ & $\begin{array}{l}\text { Tissue edema immediately following } \\
\text { the injury will hamper the judgment of } \\
\text { surgeon resulting in suboptimal } \\
\text { outcome }\end{array}$ \\
\hline
\end{tabular}

Table 59.3 Advantages and disadvantages of delayed reconstruction

\begin{tabular}{l|l}
$\begin{array}{l}\text { Advantages of delayed } \\
\text { reconstruction }\end{array}$ & $\begin{array}{l}\text { Disadvantages of delayed } \\
\text { reconstruction }\end{array}$ \\
\hline $\begin{array}{l}\text { Correction of defects after the } \\
\text { resolution of edema will give a } \\
\text { clear picture of the defect size }\end{array}$ & $\begin{array}{l}\text { Severe scar contracture, less } \\
\text { postoperative functional and } \\
\text { aesthetic outcome }\end{array}$ \\
\hline $\begin{array}{l}\text { Correction of minor deformities } \\
\text { is possible which may have } \\
\text { been missed during immediate } \\
\text { reconstruction }\end{array}$ & $\begin{array}{l}\text { Number of hospital stay is } \\
\text { increased with more psychological } \\
\text { burden to the family and patient } \\
\text { due to disfigured face }\end{array}$ \\
$\begin{array}{l}\text { The necrotic margins can be } \\
\text { easily assessed before } \\
\text { reconstruction }\end{array}$ & $\begin{array}{l}\text { High chances of infection due to } \\
\text { open wound }\end{array}$ \\
\hline
\end{tabular}

soft tissues and malunion of fractures. This grace period will allow the surgeon to have an accurate and swift identification of subtle deformities for a major single-stage intervention rather than repeated assault to soft tissues causing fibrosis and decreased vascularity.

The essential difference in the management of routine maxillofacial injury and gunshot wounds of the face is the requirement of a multidisciplinary team for the management of gunshot wounds. Therefore, a short-term delay or temporizing such wounds allows time to procure diagnostic images and study models and lastly for a discussion on inputs from the medical and surgical team. In general, the formulation of treatment plan should be based on the general health status of the patient, availability of resources, surgeon's expertise, and patient's will.

In a vast majority of cases despite the primary management approach, a significant number of gunshot injuries are plagued with residual functional and aesthetic problems. Hence, a good postoperative outcome is multifactorial and is the reflection of all the above factors and not just the early definitive repair. However, a large number of maxillofacial gunshot wounds can be treated definitively at the time of ini-
The general physical status of the patient, timing of surgery, extent of composite tissue damage, good surgical techniques, use of appropriate hardwares, antibiotics, and proper rehabilitation are the factors which determine the final outcome and aesthetic result in a penetrating facial injury.

tial intervention if the general condition of the patient and expertise of surgeon permit and the benefits of such an approach are manifold.

\subsection{Recent Advances}

Several recent advances have significantly improved the morbidity and survival rates in complex maxillofacial gunshot injuries. More importantly they serve as a support system to the surgeons, enabling them to appreciate and attend to the finer aspects of complex composite injuries. This in turn paves the way to achieve far more superior reconstructive outcomes. Contemporary techniques employ virtual surgical planning, patient-specific stereolithographic models, as well as intraoperative navigation and imaging (Refer Chap. 41 of this book). These modern-day techniques help elevate the surgical experience to one that is more precise, faster, and minimally invasive.

Composite tissue alloplastic transplantation or face transplantation is yet another recent innovation in this field. This treatment is rendered for patients with massive loss of hard and soft tissues of the face or in cases where the final outcome is suboptimal even after multiple surgeries. However, it is not in the mainstay treatment of gunshot wound of the face because of the difficulties in finding an appropriate donor, lack of expertise, requirement of long-term immunosuppressants, absence of long-term follow-up, and associated ethical issues.

\subsection{Conclusion}

In conclusion, the management strategies of patients with facial gunshot wounds are almost as diverse as the case presentation itself. This chapter ascertains that the blueprint for actions in the management of facial gunshot injuries has undergone significant change over the last decade. A new understanding of the inherent osteogenic potential of the human body in the face of contemporary warfare coupled with the availability of state-of-the-art equipments and facilities favors a brisk early approach. Thus, present guidelines 
essentially direct surgeons to do as much as possible for the gunshot patient with regard to hard and soft tissue reconstruction of the face and jaws within 48 hours. The treatment in such cases is more comprehensive with intent to simultaneously debride and reconstruct.

\section{References}

1. McLean JN, Moore CE, Yellin SA. Gunshot wounds to the faceacute management. Facial Plast Surg. 2005;21:191-8.

2. Motamedi MHK. Primary management of maxillofacial hard and soft tissue gunshot and shrapnel injuries. J Oral Maxillofac Surg. 2003;61:1390-8.

3. Robertson BC, Manson PN. High-energy ballistic and avulsive injuries. A management protocol for the next millennium. Surg Clin North Am. 1999;79:1489-502.

4. Motamedi MH, Behnia H. Experience with regional flaps in the comprehensive treatment of maxillofacial soft-tissue injuries in war victims. J Craniomaxillofac Surg. 1999;27:256-65.

5. Doctor VS, Farwell DG. Gunshot wounds to the head and neck. Curr Opin Otolaryngol Head Neck Surg. 2007;15:213-8.

6. Kummoona R. Management of missiles injuries of the facial skeleton: primary, intermediate, and secondary phases. J Craniofac Surg. 2010;21:976-81.

7. Williams CN. Immediate and long-term management of gunshot wounds to the lower face. Plast Reconstr Surg. 1988;82:433-9.

8. Shuker ST. Emergency treatment strategy and the biodynamic effects of massive, \& "chopped off" mandibular tissue and a prolapsed tongue. J Craniomaxillofac Surg. 2013;41:e59-63.

9. Chen AY, Stewart MG, Raup G. Penetrating injuries of the face. Otolaryngol Neck Surg. 1996;115:464-70.

10. Breeze J, Tong D, Gibbons A. Contemporary management of maxillofacial ballistic trauma. Br J Oral Maxillofac Surg. 2017;55:661-5.

11. Hodgetts TJ, Mahoney PF, Kirkman E. Damage control resuscitation. J R Army Med Corps. 2007;153:299-300.

12. Tong DC, Breeze J. Damage control surgery and combat-related maxillofacial and cervical injuries: a systematic review. Br J Oral Maxillofac Surg. 2016;54:8-12.

13. Jose A, Nagori SA, Agarwal B, Bhutia O, Roychoudhury A. Management of maxillofacial trauma in emergency: an update of challenges and controversies. J Emerg Trauma Shock. 2016;9:73-80.

14. Powers DB, Will MJ, Bourgeois SL, Hatt HD. Maxillofacial trauma treatment protocol. Oral Maxillofac Surg Clin North Am. 2005; 17:341-55.

15. Futran ND, Farwell DG, Smith RB, Johnson PE, Funk GF. Definitive management of severe facial trauma utilizing free tissue transfer. Otolaryngol Head Neck Surg. 2005;132:75-85.

16. Cole RD, Browne JD, Phipps CD. Gunshot wounds to the mandible and midface: evaluation, treatment, and avoidance of complications. Otolaryngol Head Neck Surg. 1994;111:739-45.

17. DuBose J, Teixeira PGR, Hadjizacharia P, Hannon M, Inaba K, Green DG, et al. The role of routine spinal imaging and immobilisation in asymptomatic patients after gunshot wounds. Injury. 2009;40:860-3.

18. Shvyrkov MB, Yanushevich OO. Facial gunshot wound debridement: debridement of facial soft tissue gunshot wounds. J Craniomaxillofac Surg. 2013;41:e8-16.

19. Cunningham LL, Haug RH, Ford J. Firearm injuries to the maxillofacial region: an overview of current thoughts regarding demo- graphics, pathophysiology, and management. J Oral Maxillofac Surg. 2003;61:932-42.

20. Tan YH, Zhou SX, Liu YQ, Liu BL, Li ZY. Small-vessel pathology and anastomosis following maxillofacial firearm wounds: an experimental study. J Oral Maxillofac Surg. 1991;49:348-52.

21. Clark N, Birely B, Manson PN, Slezak S, Kolk CV, Robertson B, et al. High-energy ballistic and avulsive facial injuries: classification, patterns, and an algorithm for primary reconstruction. Plast Reconstr Surg. 1996;98:583-601.

22. Clasper JC, Hill PF, Watkins PE. Contamination of ballistic fractures: an in vitro model. Injury. 2002;33:157-60.

23. Berlin R, Janzon B, Nordström G, Schantz B. The extent of muscle tissue damage in missile wounds one and six hours after the infliction of trauma studied by the current method of debridement. Acta Chir Scand. 1978;144:213-7.

24. Rich NM. Vietnam missile wounds evaluated in 750 patients. Mil Med. 1968;133:9-22.

25. Reis ND, Zinman C, Besser MI, Shifrin LZ, Rosen H. A philosophy of limb salvage in war: use of the fixateur externe. Mil Med. 1991;156:505-20.

26. Al-Shawi A. Experience in the treatment of missile injuries of the maxillofacial region in Iraq. Br J Oral Maxillofac Surg. 1986;24:244-50.

27. Zhou S, Lei D, Liu Y, Tan Y, Gu X. Experimental study on firearm wound in maxillofacial region. Chin Med J. 1998;111:114-7.

28. Suominen E, Tukiainen E. Close-range shotgun and rifle injuries to the face. Clin Plast Surg. 2001;28:323-37.

29. Petersen K, Hayes DK, Blice JP, Hale RG. Prevention and management of infections associated with combat-related head and neck injuries. J Trauma. 2008;64:S265-76.

30. Mellor SG, Cooper GJ, Bowyer GW. Efficacy of delayed administration of benzylpenicillin in the control of infection in penetrating soft tissue injuries in war. J Trauma. 1996;40:S128-34.

31. Hospenthal DR, Murray CK, Andersen RC, Bell RB, Calhoun JH, Cancio LC, et al. Executive summary: guidelines for the prevention of infections associated with combat-related injuries: 2011 update. J Trauma Inj Infect Crit Care. 2011;71:S202-9.

32. Ray JM. The Treatment of Maxillofacial Trauma in Austere Conditions. Atlas Oral Maxillofac Surg Clin. 2013;21:9-14.

33. Kummoona R, Muna AM. Evaluation of immediate phase of management of missile injuries affecting maxillofacial region in Iraq. J Craniofac Surg. 2006;17:217-23.

34. Xavier SP, de Barros Pontes C, Silva ER, de Santana Santos T, Zatiti SC, de Mello Filho FV. Three-stage mandible reconstruction after firearm injury. J Craniofac Surg. 2013;24:e87-8.

35. Tan Y, Zhou S, Liu Y, Li Z. A gross and microscopic study of cerebral injuries accompanying maxillofacial high-velocity projectile wounding in dogs. J Oral Maxillofac Surg. 1998;56:345-8.

36. Behnia H, Motamedi MH. Reconstruction and rehabilitation of short-range, high-velocity gunshot injury to the lower face: a case report. J Craniomaxillofac Surg. 1997;25:220-7.

37. Gassner HG, Sherris DA, Otley CC. Treatment of facial wounds with botulinum toxin A improves cosmetic outcome in primates. Plast Reconstr Surg. 2000;105:1948-53.

38. Manson PN, Crawley WA, Yaremchuk MJ, Rochman GM, Hoopes JE, French JH. Midface fractures: advantages of immediate extended open reduction and bone grafting. Plast Reconstr Surg. 1985;76:1-12.

39. Kaufman Y, Cole P, Hollier L. Facial gunshot wounds: trends in management. Craniomaxillofac Trauma Reconstr. 2009;2:85-90.

40. Hollier L, Grantcharova EP, Kattash M. Facial gunshot wounds: a 4-year experience. J Oral Maxillofac Surg. 2001;59:277-82. 
41. Mladick RA, Georgiade NG, Royer J. Immediate flap reconstruction for massive shotgun wound of face. Case report. Plast Reconstr Surg. 1970;45:186-8.

42. Vásconez HC, Shockley ME, Luce EA. High-energy gunshot wounds to the face. Ann Plast Surg. 1996;36:18-25.

43. Spira M, Hardy SB, Biggs TE, Gerow FJ. Shotgun injuries of the face. Plast Reconstr Surg. 1967;39:449-58.
44. Kassan AH, Lalloo R, Kariem G. A retrospective analysis of gunshot injuries to the maxillofacial region. SADJ. 2000;55:359-63.

45. Finch DR, Dibbell DG. Immediate reconstruction of gunshot injuries to the face. J Trauma. 1979;19:965-8.

46. Gruss JS, Antonyshyn O, Phillips JH. Early definitive bone and soft-tissue reconstruction of major gunshot wounds of the face. Plast Reconstr Surg. 1991;87:436-50.

Open Access This chapter is licensed under the terms of the Creative Commons Attribution 4.0 International License (http://creativecommons. org/licenses/by/4.0/), which permits use, sharing, adaptation, distribution and reproduction in any medium or format, as long as you give appropriate credit to the original author(s) and the source, provide a link to the Creative Commons license and indicate if changes were made.

The images or other third party material in this chapter are included in the chapter's Creative Commons license, unless indicated otherwise in a credit line to the material. If material is not included in the chapter's Creative Commons license and your intended use is not permitted by statutory regulation or exceeds the permitted use, you will need to obtain permission directly from the copyright holder. 